\title{
A mutation in LaCDWARF1 results in a GA-deficient dwarf phenotype in sponge gourd (Luffa acutangula)
}

\author{
Gangjun Zhao ${ }^{1}$ Caixia Luo ${ }^{1,2}$. Jianning Luo ${ }^{1}$ Junxing $\mathrm{Li}^{1} \cdot$ Hao Gong ${ }^{1} \cdot$ Xiaoming Zheng $^{1} \cdot$ Xiaoxi Liu $^{1}$ - Jinju Guo ${ }^{1}$. \\ Lingyan $\mathrm{Zhou}^{2} \cdot$ Haibin $\mathrm{Wu}^{1}$ (1)
}

Received: 6 July 2020 / Accepted: 7 December 2020 / Published online: 14 August 2021

(c) The Author(s) 2021

\begin{abstract}
Key message A dwarfism gene LacDWARF1 was mapped by combined BSA-Seq and comparative genomics analyses to a $65.4 \mathrm{~kb}$ physical genomic region on chromosome 05 .

Abstract Dwarf architecture is one of the most important traits utilized in Cucurbitaceae breeding because it saves labor and increases the harvest index. To our knowledge, there has been no prior research about dwarfism in the sponge gourd. This study reports the first dwarf mutant WJ209 with a decrease in cell size and internodes. A genetic analysis revealed that the mutant phenotype was controlled by a single recessive gene, which is designated Lacdwarfl (Lacd1). Combined with bulked segregate analysis and next-generation sequencing, we quickly mapped a $65.4 \mathrm{~kb}$ region on chromosome 5 using $\mathrm{F}_{2}$ segregation population with InDel and SNP polymorphism markers. Gene annotation revealed that Lac05g019500 encodes a gibberellin $3 \beta$-hydroxylase (GA3ox) that functions as the most likely candidate gene for Lacd1. DNA sequence analysis showed that there is an approximately $4 \mathrm{~kb}$ insertion in the first intron of Lac05g019500 in WJ209. Lac05g019500 is transcribed incorrectly in the dwarf mutant owing to the presence of the insertion. Moreover, the bioactive GAs decreased significantly in WJ209, and the dwarf phenotype could be restored by exogenous $\mathrm{GA}_{3}$ treatment, indicating that WJ209 is a GA-deficient mutant. All these results support the conclusion that Lac05g019500 is the Lacdl gene. In addition, RNA-Seq revealed that many genes, including those related to plant hormones, cellular process, cell wall, membrane and response to stress, were significantly altered in WJ209 compared with the wild type. This study will aid in the use of molecular markerassisted breeding in the dwarf sponge gourd.
\end{abstract}

\section{Introduction}

The sponge gourd $(2 n=26)$ is an important vegetable and medicinal plant in tropical and subtropical regions, and has a long history of cultivation in Asian and African tropical countries (Kalloo 1993; Wu et al. 2014, 2016). The sponge gourd is a member of the Cucurbitaceae and has nine species, but only Luffa acutangula (L.) Roxb. and L. cylindrica

Communicated by Amnon Levi.

Haibin $\mathrm{Wu}$

wuhbhope@yeah.net

1 Guangdong Key Laboratory for New Technology Research of Vegetables, Vegetable Research Institute, Guangdong Academy of Agricultural Sciences, Guangzhou 510640, Guangdong, China

2 College of Agriculture \& Biology, Zhongkai University of Agriculture and Engineering, Guangzhou 510225, Guangdong, China
(L.) Roem. are domesticated (Gautam et al. 2017; Wu et al. 2014). Its tender fruits are rich in vitamin A, vitamin $\mathrm{C}$, and iron and have high nutritional value (Dubey et al. 2015; Xu et al. 2008). In addition, the sponge gourd possesses multiple potential biological and therapeutic activities in the management of hepatoprotective, antidiabetic, antiulcer, anticancer, fungistatic, analgesic, antimicrobial, immunomodulatory(Kuppast and Mankani 2012; Shendge and Belemkar 2018), and anti-HIV-1 activities(Ng et al. 2011).

Height is one of the most important traits in plant breeding. Dwarfism can save labor in management and harvesting, improve lodging resistance and increase the harvest index (Peng et al. 1999). The semi-dwarf variety of rice (Sasaki et al. 2002; Suh 1978), increases the yield potential and nitrogen responsiveness, resulting in an increase in the harvest index of more than $60 \%$ (Khush 2001; Peng et al. 1999), which constitutes an important breakthrough in the history of crop improvement. This remarkable achievement 
is referred to as the "Green Revolution" (Khush 2001; Peng et al. 1999).

Over recent years, dozens of genes regulating plant height have been identified from rice, wheat, cucumber, and other plants (Hou et al. 2017; Li et al. 2013; Magome et al. 2004; Sasaki et al. 2002). Many of these genes affect the synthesis and signal transduction of hormones, such as gibberellin(Sasaki et al. 2002; Ueguchi-Tanaka et al. 2005), brassinolide(Chory et al. 1991; Hou et al. 2017; Schwessinger et al. 2011), auxin (Li et al. 2018) and strigolactones (Kohlen et al. 2012) that affect cell elongation or development.

Gibberellins (GAs) regulate diverse plant developmental processes, such as seed germination, stem elongation, flowering, and fruit development (Silverstone and Sun 2000; Wang et al. 2015). Dwarfs will be formed if the genes in GA synthesis or signal transduction are mutated. For example, mutations in ent-kaurenoic acid oxidase (KAO) (Fambrini et al. 2011; Regnault et al. 2014), ent-copalyl diphosphate synthase (CPS) (Magome et al. 2004), the wellknown "Green Revolution" genes GA20-oxidases (Sasaki et al. 2002; Zhai et al. 2019), or GA3ox (Chen et al. 2014; Mitchum et al. 2006; Wei et al. 2019) in GA synthesis, reduce the levels of endogenous GAs and lead to dwarfism. The GAs receptor (gibberellin-insensitive dwarf protein1, GID1) (Shimada et al. 2008) and several repressor proteins (DELLA) (Murase et al. 2008) form a complex to precisely regulate the responses of plants to GAs.

Bulked segregant analysis (BSA) coupled with nextgeneration sequencing (NGS) provides a rapid and efficient method to map genes and QTLs (Takagi et al. 2013). BSA was used to identify markers using bulked sample pools (Michelmore et al. 1991). Whole-genome sequencing can be a powerful tool for the identification of variations between different varieties (Bentley 2006). The improvement in technologies and substantial reduction in the cost of NGS enabled the coupling of whole-genome resequencing with BSA (BSA-Seq). BSA-Seq has been successfully used in many crops (Zou et al. 2016), including cucumber (Song et al. 2020), watermelon (Wei et al. 2019) and melon (Zhang et al. 2019).

Dwarfism is an important trait in Cucurbitaceae breeding. Dwarf plants are suitable for intercropping, and in turn improve the index of multiple cropping and increase the yield per unit area (Li et al. 2016). Owing to its contribution to yield and reduction in labor in management and harvesting, dwarfism is an important agronomic trait for selection in Cucurbitaceae breeding. Until now, there have been many studies on dwarf vines in many Cucurbitaceae crops including pumpkin (Zhang et al. 2015), cucumber (Hou et al. 2017), watermelon (Dong et al. 2018; Hexun et al. 1998; Wei et al. 2019) and melon (Hwang et al. 2014). In addition, a compact cucumber has been proposed for use in the high-wire cultivation of European greenhouse cucumbers (Li et al. 2011). Sponge gourd has similar growth habits with other cucurbitaceous crops, and short vines are also important breeding traits. However, to our knowledge, there have not been any relevant report studies conducted on it.

In this study, we identified a dwarf mutant of sponge gourd, WJ209, and genetic analysis showed that the mutant phenotype was controlled by a single recessive gene. By using BSA-Seq, we identified Lac05g019500, which encoded a gibberellin 3 $\beta$-hydroxylase (GA3ox), the key enzyme in bioactive GAs production, and served as the most likely candidate gene for the dwarfism phenotype of WJ209. An insertion of approximately $4 \mathrm{~kb}$ was found in the first intron of mutant allele. This insertion caused the incorrect transcription of $\mathrm{Lac05} \mathrm{g} 019500$, resulting reduction in the amount of bioactive GAs in WJ209, which is responsible for the dwarfism phenotype in sponge gourd. This study could aid in the use of molecular marker-assisted breeding in the dwarf sponge gourd.

\section{Materials and methods}

\section{Plant materials and populations}

The WT is an inbred line of sponge gourd. WJ209, the dwarf mutant, is a natural mutation obtained from the field production process of WT. After three generations of selfing, WJ209 was crossed to S1174 (the inbred line for wholegenome sequencing), and the $F_{1}$ was self-pollinated to produce $\mathrm{F}_{2}$ progeny. The $323 \mathrm{~S} 1174 \times \mathrm{WJ} 209 \mathrm{~F}_{2}$ was used to examine the segregation and identification of candidate gene.

\section{Histological analysis of WT and WJ209}

The third internode down from the growth point at 5-weekold plants was cut into 3-mm pieces and fixed in a formaldehyde-acetic acid-alcohol (FAA) solution (70\% alcohol: $3.8 \%$ formalin: glacial acetic acid $=18: 1: 1$ ) fixative for $24 \mathrm{~h}$. The samples were then dehydrated with different concentrations of ethanol, embedded in paraffin, cut into $10-\mu \mathrm{m}$ slices, stained with $1 \%$ toluidine blue for $5 \mathrm{~min}$, and washed with deionized water and ethanol (Sun et al. 2017). Next, the paraffin sections were observed and imaged using LSM710 microscopy (Zeiss, Germany).

\section{WT and WJ209 treatment with exogenous $\mathrm{GA}_{3}$}

The germinated seeds were sown in plastic pots (size: $7 \times 7 \times 7 \mathrm{~cm})$ and grown at $26 \pm 2{ }^{\circ} \mathrm{C}$ in a climate-controlled room with a $16 \mathrm{~h} / 8 \mathrm{~h}$ light/dark cycle. At the two-leaf stage, the treated leaves were sprayed with $100 \mu \mathrm{M} \mathrm{GA}_{3}$, while 
the controls seedlings were sprayed with water. Three biological replicates, each with 10 plants, were sprayed four times once every other day. The height from cotyledons to the growing point was measured 3 days after the final treatment. In addition, untreated WT and WJ209 seedlings at the three-leaf stage and whole plant were sampled to quantify the endogenous GAs and proceed with RNA sequencing. Three biological replicates, each with nine plants, were frozen in liquid nitrogen and stored at $-80{ }^{\circ} \mathrm{C}$ until use.

\section{Quantify chlorophyll content}

WT and WJ209 seedlings at the 3-week-old were used to quantify the chlorophyll content (SPAD) by using plant nutrient analyzer (TYS-4N, TOP Instrument, China). After instrument calibration, the first expanded leaf was clamped by instrument receiving window (ensure fully covered) and recorded the reading.

\section{Quantification of Endogenous GAs}

The sample were prepared and analyzed as previously described (Plackett et al. 2012). In brief, fine powder sponge gourd seedlings $(1 \mathrm{~g})$ were extracted with $10 \mathrm{ml}$ acetonitrile for $12 \mathrm{hrs}$ at $4{ }^{\circ} \mathrm{C}$. Deuterated gibberellin (OIChem, Czechoslovakia) was added to the plant samples to serve as an internal standard. After 5 mins of centrifugation at $12,000 \mathrm{~g}$ at $4{ }^{\circ} \mathrm{C}$, the supernatant was removed. A solution of five times the volume of acetonitrile was added to the precipitate and extracted twice. The resulting supernatants were combined, and $\mathrm{C} 18$ and GCB were added to purify the impurities, and centrifuged at $12,000 \mathrm{~g}$ for $5 \mathrm{mins}$ at $4{ }^{\circ} \mathrm{C}$. The supernatant was then evaporated with nitrogen and reconstituted with $200 \mu \mathrm{l}$ of methanol. The content of GAs was determined with an HPLC (AGLIENT1290, AGLIENT, USA) coupled with tandem mass spectrometry (SCIEX-6500Qtrap, AB SCIEX, USA).

\section{Whole-genome re-sequencing}

Fifty normal height plants and 50 dwarf plants were randomly selected from the $\mathrm{F}_{2}$ population. Genomic DNA was extracted from each individual using the CATB method (Murray and Thompson 1980), and the samples were mixed into two DNA pools: one of N-bulk for normal height plants and one for M-bulk for dwarfs. Simultaneously, the WJ209 genomic DNA was extracted to serve as the parent pool. Sequencing libraries from each pool were generated using a Truseq Nano DNA HT Sample Preparation Kit (Illumina, USA) following the manufacturer's recommendations, sequenced by an Illumina HiSeq4000 platform, and 150-bp paired-end reads were generated. The depth of sequencing data of N-bulk and M-bulk was not less than 50×, and that of the parent pool were not less than $10 \times$.

\section{Data analysis and marker development}

The quality of the BSA-Seq data was evaluated using FastQC software (Andrews 2010). Clean reads were obtained by removing reads containing adapter or low-quality reads. BWA software (Li and Durbin 2009) was used to align the clean reads with the reference genome S1174 (data not shown) and convert Sam files to Bam files (Li et al. 2009). Potential PCR duplications were removed using SAMtools software (Li et al. 2009). GATK software (McKenna et al. 2010) was used to call variants between the N-bulk and M-bulk and between the parent-pool and reference genome, respectively. After removing the SNP/InDel index in both pools with less than 0.3 or more than 0.7 , we calculated the delta SNP/InDel index using Perl scripts and drew a Manhattan Plot using R scripts. Primers of potential InDel-based markers and SNP markers between WJ209 and S1174 were designed using Primer Premier 5.0.

\section{RNA-Sequencing and data analysis}

Sequencing libraries were generated using an NEBNext UltraTM RNA Library Prep Kit for Illumina (NEB) following the manufacturer's instructions. The libraries were sequenced on an Illumina Nova-Seq platform, and 150-bp paired-end reads were generated. The quality of RNA-Seq data was evaluated using FastQC software (Andrews 2010). Clean data were obtained by removing adapter or lowquality reads from the raw data. The Hisat2 program (Kim et al. 2015) was used to align the clean reads with reference genome S1174 (data not shown), and the Sam files were converted to Bam files using SAMtools software ( $\mathrm{Li}$ et al. 2009). The level of gene expression was quantified using featureCounts (Liao et al. 2014). The DESeq2 (Love et al. 2014) R package was used to determine the DEGs. Genes with an adjusted $P$ value (padj) $<0.05$ and llog (fold change) $\mid \geq 1$ were assigned as differentially expressed.

\section{Amplification of the insertion}

KOD-Plus-Neo (TOYOBO, code No. KOD-401) was used to amplify the insertion. PCR components included the following: $32 \mu \mathrm{ldd} \mathrm{H}_{2} \mathrm{O}, 5 \mu \mathrm{l} 10 \times$ PCR Buffer, $5 \mu \mathrm{l} 2 \mathrm{mM}$ dNTPs, $3 \mu 125 \mathrm{mM} \cdot \mathrm{MgSO}_{4}, 1.5 \mu \mathrm{l} 10 \mathrm{pmol} / \mu \mathrm{l}$ primer $\mathrm{F}$, $1.5 \mu 10 \mathrm{pmol} / \mu 1$ primer R, $1 \mu \mathrm{l}$ KOD-Plus-Neo (1.0 U/ $\mu \mathrm{l})$, and $1 \mu \mathrm{l}$ genomic DNA $(100 \mathrm{ng} / \mu \mathrm{l})$, in a total reaction volume of $50 \mu \mathrm{l}$. The PCR cycle conditions were as follows: pre-denaturation $94{ }^{\circ} \mathrm{C} 2 \mathrm{~min}$, denaturation $98{ }^{\circ} \mathrm{C} 10 \mathrm{sec}$, annealing $58^{\circ} \mathrm{C} 30 \mathrm{sec}$, extension $68^{\circ} \mathrm{C} 2.5 \mathrm{~min}, 33$ cycles, and $68{ }^{\circ} \mathrm{C} 5 \mathrm{~min}$, with storage at $4{ }^{\circ} \mathrm{C}$. 


\section{GA3ox homolog identification and phylogenetic analysis}

For the genome-wide identification of GA3oxs in other Cucurbitaceae species, including Cucumis sativus, Cucumis melo, Citrullus lanatus, Cucurbita maxima and Lagenaria siceraria, the genome and amino acid sequences were downloaded from the Cucurbit Genomics Database (http://cucur bitgenomics.org/), and amino acid sequences of Arabidopsis thaliana GA3oxs (AtGA3OX1: AT1G15550.1, AtGA3OX2: AT1G80340.1, AtGA3OX3: AT4G21690.1, AtGA3OX4: $A T 1 G 80330.1)$ were used as queries to blast against the protein file of other Cucurbitaceae species using the BLASTp program $\left(E\right.$-value $\left.<1 \mathrm{e}^{-5}\right)$.

The amino acid sequences of GA3oxs were aligned using ClustalX (Larkin et al. 2007). MEGA7 (Kumar et al. 2016) was applied to construct the phylogenetic tree using the neighbor-joining method with 1000 bootstrap replicates. The motif of proteins was predicted using MEME online software (http://meme-suite.org/tools/meme) with the maximum number of motifs equal to 10 and the maximum width equal to 100 .

\section{Results}

\section{Morphology of the dwarf mutant}

The dwarf mutant WJ209 was much shorter than the wild type (WT) (Fig. 1a). The total length of WJ209 $(49.4 \pm 4.7 \mathrm{~cm}, 14$ internodes) was reduced to $19.2 \%$ relative to the WT $(256.8 \pm 23.1 \mathrm{~cm}, 20$ internodes) (Fig. $1 \mathrm{~b}$ and $\mathrm{c})$, while the stem diameter and leaf thickness increased (Fig. 1d and e). In addition, the leaf of WJ209 turned dark-green and chlorophyll content (SPAD) increased (Supplementary Fig. S1). Moreover, the cell length of longitudinal section significantly decreased in WJ209 $(43.3 \pm 6.9 \mu \mathrm{m})$ compared with that of the WT $(70.1 \pm 12.3 \mu \mathrm{m})($ Fig. 1f, g).

\section{WJ209 is a GA biosynthetic-deficient mutant}

Bioactive GAs play an essential role in stem elongation, and the plant will be dwarf if the genes involved in GAs syntheses are mutated (Sasaki et al. 2002; Silverstone and Sun 2000). To test whether GAs regulate the height of dwarf mutant, the mutant was treated with $100 \mu \mathrm{M} \mathrm{GA}$. $\mathrm{GA}_{3}$ promotes stem internode elongation, and the height of WJ209 and the WT increased significantly after treatment with exogenous $\mathrm{GA}_{3}$ (Fig. 2). In addition, the height of WJ209 $(11.5 \pm 2.4 \mathrm{~cm})$ after treatment with exogenous $\mathrm{GA}_{3}$ did not differ from that of the WT $(12.4 \pm 1.0 \mathrm{~cm})$ when it was treated with water (Fig. 2b). To confirm whether the biosynthesis of GA was impaired in WJ209, the levels of endogenous GAs were measured in WJ209 and the WT (Fig. 2c). The levels of bioactive $\mathrm{GA}_{1}, \mathrm{GA}_{3}$ and $\mathrm{GA}_{4}$ decreased significantly in WJ209 compared with the levels in WT, while the content of their immediate precursors, $\mathrm{GA}_{9}$ and $\mathrm{GA}_{20}$, increased (Fig. 2c), suggesting that the dwarf phenotype is associated with decreased levels of bioactive GAs. Taken together, these results confirmed that WJ209 is a GA biosynthetic-deficient mutant.

\section{Genetic analysis of the dwarf mutant}

To analyze the genetic characteristics of the dwarf phenotype, WJ209 was crossed with S1174 (the inbred line for whole-genome sequencing). The $\mathrm{F}_{1}$ plants exhibited wildtype phenotypes, suggesting that the mutant trait is recessive. The $\mathrm{F}_{2}$ progeny exhibited a segregation ratio of $3: 1$ (Normal: Dwarfism $=235: 88, \chi^{2}=0.87 ; P=0.352$ ). Therefore, we concluded that the dwarf phenotype of WJ209 is controlled by a single recessive gene and designated it Lacdwarfl (Lacd1).

\section{Mapping of the Lacd1 gene by BSA-Seq}

A bulked segregant analysis combined whole-genome re-sequencing (BSA-Seq) strategy was applied to rapidly identify Lacdl using $323 \mathrm{~F}_{2}$ plants from S1174 × WJ209. The dwarf mutant (WJ209), normal-type bulk (N-bulk) and mutant bulk (M-bulk) were obtained with $9.7 \mathrm{~Gb}(12.4 \times)$, $46.1 \mathrm{~Gb}(59.1 \times)$, and $45.8 \mathrm{~Gb}(58.7 \times)$ raw data, respectively (Supplementary Table S1). The $\Delta$ (SNP-index) was calculated and plotted against the genomic positions. The results revealed that there was only one candidate interval responsible for dwarfism in the 49.7-55.3 Mb region on chromosome 5 (Fig. 3a).

To fine-map Lacd1, we searched variants between WJ209 and S1174 in this candidate chromosome region, and then developed InDel and SNP markers (Supplementary Table S2). Polymorphic InDel and SNP markers were used to genotype the dwarf individuals of $\mathrm{F}_{2}$ population. First, a marker designated M5256 was designed at the peak position to detect the $F_{2}$ population. We found 73 dominant homozygous lines, 165 heterozygous lines, and 85 recessive homozygous lines, and the ratio was consistent with Mendel's law of segregation $(P>0.05)$. This indicates that there is a gene that controls vine growth near the peak. Molecular markers were developed in the target range to detect individual recombinant plants. The A-E individual plants had short vines, and the target gene was excluded from the region between M4972 and M5308 markers. The G-I individual plants also had short vines, and thus, the target gene was excluded from the region between M5330 and M5535. Simultaneously, the F individual plant displayed a normal vine phenotype, and therefore, the target gene was 


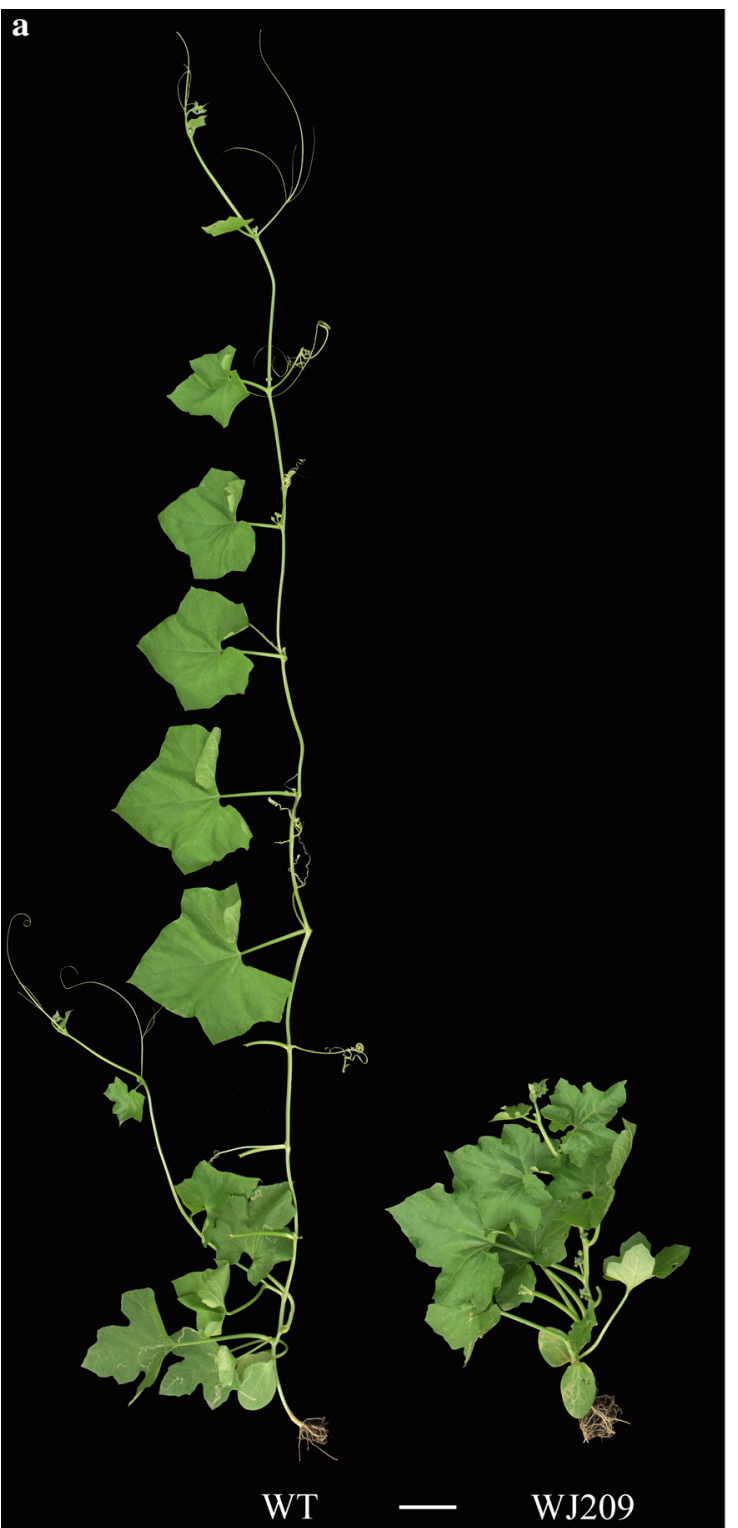

Fig. 1 Phenotypic characterization of the normal line WT and dwarf mutant WJ209 of the sponge gourd. a Phenotypes of WT and WJ209. Bar, $10 \mathrm{~cm}$. b Plant height. c Internode numbers. d Stem diameter. e Leaf thickness. f Longitudinal sections of the internodes. Bar, 100

excluded from the region between M4972 and M5324 markers. A comprehensive analysis shows that the target gene is located between M5324 and M5330. Finally, Lacd1 was fine-mapped in a $65.4 \mathrm{~kb}$ interval between the SNP markers M5324 and M5330 (Fig. 3b).

\section{Candidate gene analysis of Lacd1}

The genomic annotation indicated that the $65.4 \mathrm{~kb}$ interval encodes five genes (Fig. 3c, Table 1). There was no difference in gene expression and structure between WT and WJ209 in Lac05g019490, Lac05g019510, Lac05g019520
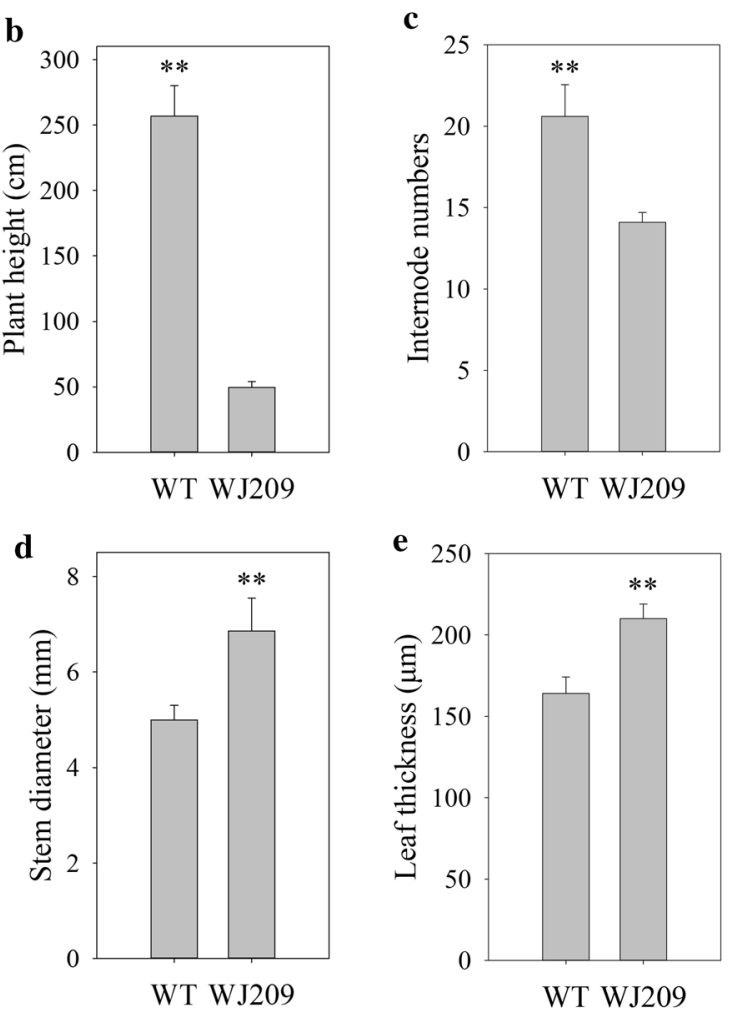

\section{f}
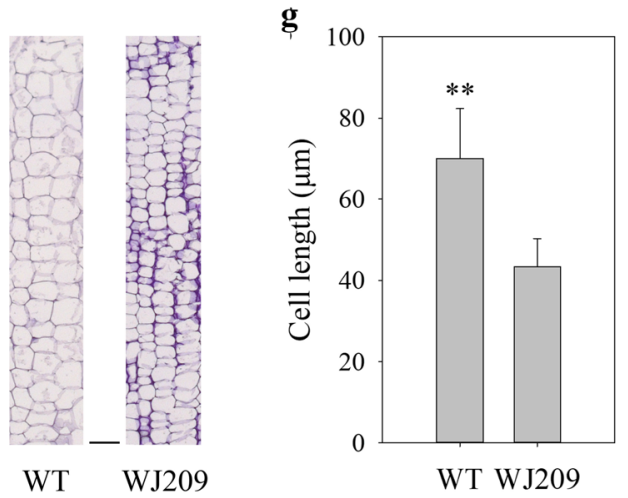

$\mu \mathrm{m}$. $\mathrm{g}$ The cell length is shown in $\mathrm{f}$. The asterisks indicate significant differences (Student's $t$ test): $* * p<0.01, n \geq 15$. Error bars represent the mean $\pm \mathrm{SD}$

and Lac05g019530 based on the resultes of RNA-Seq (Supplementary Fig. S2) and Sanger sequencing after having amplified the gene in the target region. Lac05g019520 encoded katanin p60 ATPase-containing subunit A1. Research shows that katanin p60 ATPase is involved in cellular process (Aragão et al. 2017). It's the same as Lac05g019490, Lac05g019510, and Lac05g019530, no studies have shown that the proteins encoded by Lac05g019490, Lac05g019510, and Lac05g019530 were related to plant growth and development, and there was no difference in gene structure and expression between WT and WJ209. However, analyses of the sequencing data of 
Fig. 2 Recovery of the dwarf mutant by treatment with exogenous $\mathrm{GA}_{3}$. a Seedlings treated with $100 \mu \mathrm{m} \mathrm{GA}_{3}$ or water. Bar, $2 \mathrm{~cm}$. b Height of the treated Seedlings. c Endogenous levels of GAs in WJ209 and WT. Different letters in $\mathrm{b}$ refer to their significance at $p<0.05$ (Duncan's test). The asterisks indicate significant differences (Student's t test): * $p<0.05$, $* * p<0.01$. Error bars represent the mean $\pm \mathrm{SD}$

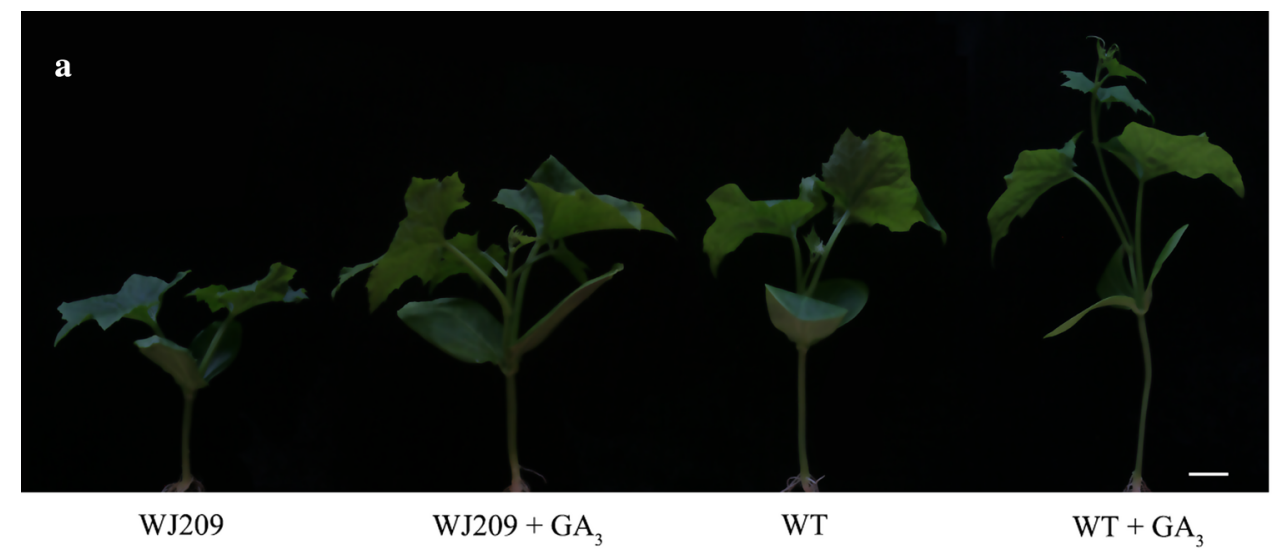

b

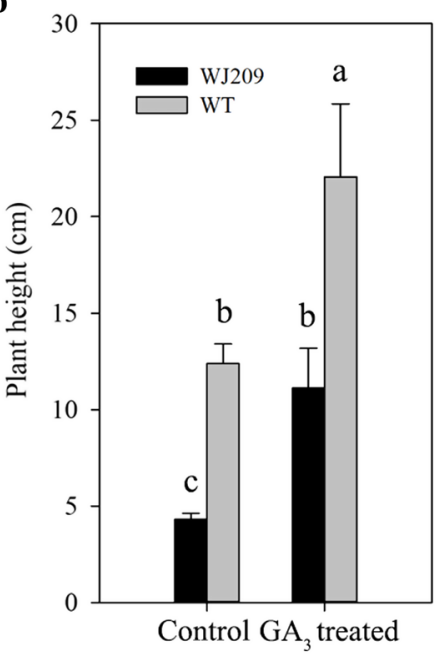

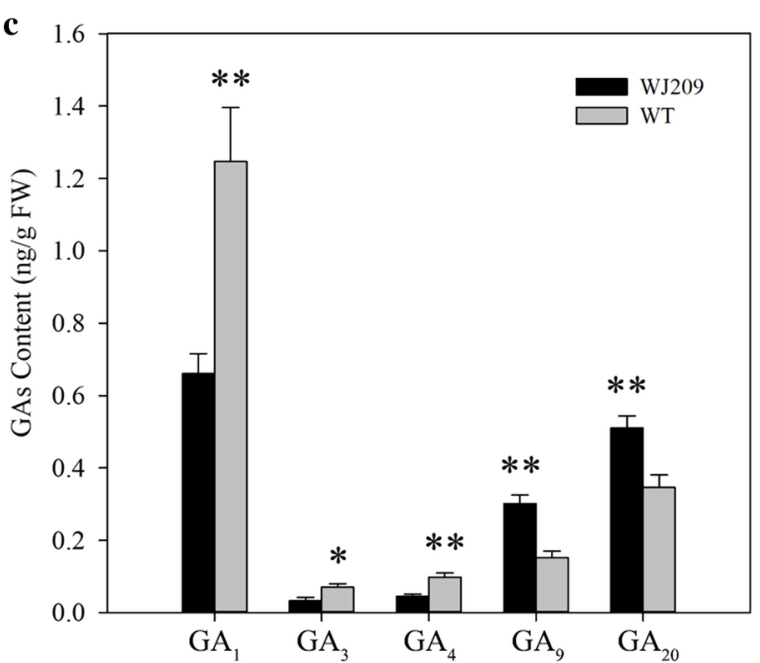

WJ209 showed that there could be a large fragment insertion at the first intron of $\mathrm{Lac05g019500} \mathrm{(Fig.} \mathrm{4).} \mathrm{The} \mathrm{M-bulk}$ also appeared to have this insertion; however, the N-bulk lacked it (Fig. 4). Simultaneously, only the Lac05g019500 expression decreased significantly in WJ209 compared with that of the WT (Supplementary Table S3). Next, a pair of primers (SV-F/R) was designed to amplify this potential insertion (Supplementary Table S2). As expected, a 243-bp DNA fragment was amplified by the primers in the WT, while it was approximately $4 \mathrm{~kb}$ in WJ209 (Supplementary Fig. S3). To confirm the genomic variations observed above, we cloned the insertion sequence in $323 \mathrm{~F}_{2}$ plants derived from $\mathrm{S} 1174 \times \mathrm{WJ} 209$. All the dwarf plants were able to amplify the homozygous $4 \mathrm{~kb}$ insertion fragment, while the normal plants were able to amplify homozygous 243 bp DNA fragments or heterozygous fragments (243 bp and $4 \mathrm{~kb}$ insertion fragment). The RNA-Seq data indicated that this insertion resulted in the incorrect transcription of $\mathrm{Lac05g019500}$ and could not amplify the complete cDNA in WJ209 (Supplementary Fig. S4). It is notable that Lac05g019500 encoded the gibberellin synthetic enzyme GA3-oxidase 1 (GA3ox1), which is the key enzyme in the production of bioactive GAs. Taken together with the fact that WJ209 is a GA biosynthetic-deficient mutant, the dwarf phenotype of WJ209 was probably caused by the mutation in Lac05g019500. Therefore, Lac05g019500 is the Lacd1 gene.

\section{Differentially expressed genes in WJ209 and WT}

To investigate the molecular mechanisms that underlie the WJ209 dwarf, a comparative transcriptome analysis was used to identify the differentially expressed genes (DEGs) between WJ209 and WT. There were 894 DEGs between the WJ209 and WT, including 408 up-regulated and 486 down-regulated genes. Gene Ontology enrichment revealed that many significantly changed genes were enriched in cellular processes (Fig. 5, Supplementary Tables S4 and S5), such as cellular process (GO:0009987) and cellular anatomical entity (GO:0110165). It is particularly notable that the expression of many genes related to cellular metabolic process (GO:0044237), membrane (GO:0016020), cell wall (GO:0005618), plasma membrane (GO:0005886), cell periphery (GO:0071944) and intrinsic component of membrane (GO:0031224), was significantly reduced in WJ209 (Fig. 5, Supplementary Fig. S5 and Supplementary 


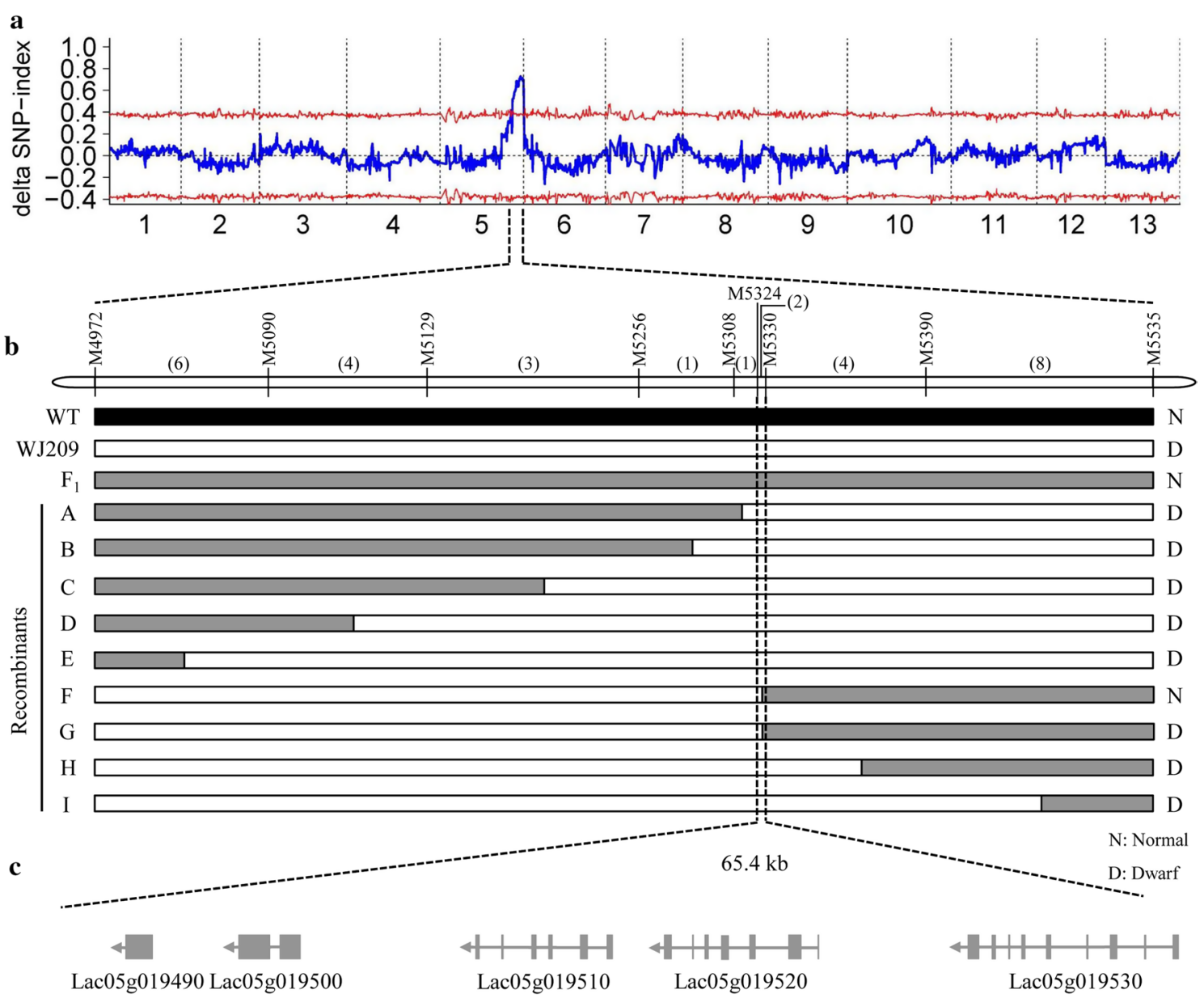

Fig. 3 Mapping of the dwarfism gene. a Delta SNP-index distribution on chromosomes. b Fine mapping of Lacd1.The numbers within brackets indicate the number of recombinants. $\mathbf{c}$ Structure of the predicted genes in mapping interval

Table 1 Genes in the mapping interval

\begin{tabular}{ll}
\hline Gene ID & Annotation \\
\hline Lac05g019490 & LINE-1 retrotransposable element ORF2 protein \\
Lac05g019500 & Gibberellin 3-beta-dioxygenase 1-like \\
Lac05g019510 & Uncharacterized \\
Lac05g019520 & Katanin p60 ATPase-containing subunit A1 \\
Lac05g019530 & Aromatic aminotransferase ISS1 \\
\hline
\end{tabular}

Table S4). We also found that plant hormone metabolic, transport, response and signaling pathway-related genes were significantly changed, including the hormone biosynthetic process (GO:0042446), regulation of hormone levels (GO:0010817), hormone metabolic process (GO:0042445), response to hormone (GO:0009725), cellular response to hormone stimulus (GO:0032870), hormone transport (GO:0009914) and hormone-mediated signaling pathway (GO:0009755) (Supplementary Fig. S6, Supplementary Tables S4 and S5). Simultaneously, many significantly changed genes were enriched in responses to stress, such as response to stress (GO:0006950), response to stimulus (GO:0050896), defense response (GO:0006952), and response to biotic stimulus (GO:0009607) (Fig. 5, Supplementary Tables S4 and S5).

\section{Analysis of the expression of GAs biosynthetic and signaling pathways and regulatory genes}

The synthesis of bioactive gibberellin is a complex process, and the genes that encode functional enzymes at each step have been well characterized (Claeys et al. 2014; Hedden and Proebsting 1999). To study the pattern of expression of the GAs biosynthetic pathway-related genes in WJ209, we utilized the homologous amino acid sequences from Arabidopsis as queries and combined them with genomic annotation. We retrieved one $C P S$, one $K A O$, three GA20oxs, two GA3oxs, four GA2oxs, and four DELLAs (Fig. 6a). In addition, we retrieved 17 genes regulated by GAs based on genomic annotation and GO annotation (Fig. 6b). Compared 


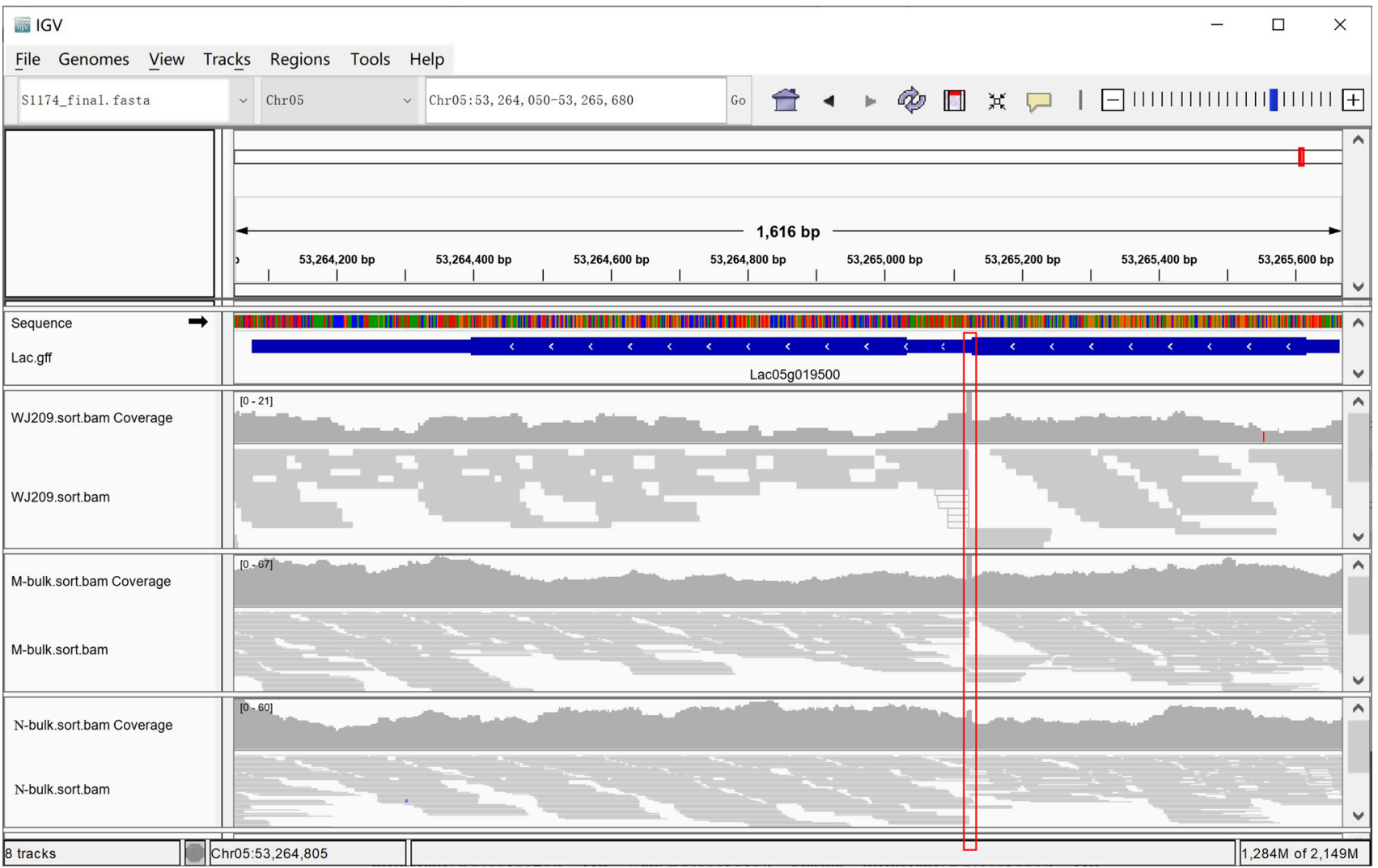

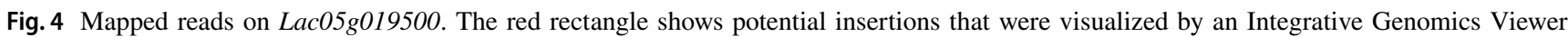
(IGV) (Robinson et al. 2011) (colour figure online)

with the profiles of expression of the WT, the expression

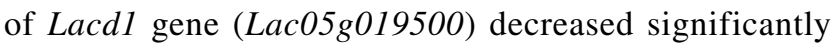
in WJ209 (Fig. 6a). The other GAs biosynthetic-related genes, including $C P S, K A O, G A 20 o x$, and an additional GA3ox, were up-regulated (Fig. 6a). Similarly, three GA2ox homologs were up-regulated in WJ209, while only one (Lac1 1 g006800) was significantly down-regulated (Fig. 6a). In addition, one DELLA (Lac05g016710) was significantly up-regulated, while three other DELLAs had no obvious difference in WJ209 compared with that of the WT (Fig. 6a). In addition, nine genes regulated by GAs were significantly down-regulated, while eight genes regulated by GAs had no obvious difference or were up-regulated in WJ209 compared with that of the WT (Fig. 6b).

\section{Phylogenetic analysis of GA3oxs in the Cucurbitaceae}

To better understand the relationship between Lacdl and its homologues in other species in the Cucurbitaceae family, we identified 28 homologs from other cucurbit species, including Cucumis sativus, Cucumis melo, Citrullus lanatus, Cucurbita maxima and Lagenaria siceraria (Fig. 7). The results of the neighbor-joining tree indicated that the
GA3oxs genes were divided into three groups with similar motifs shown by conservative motif analysis, and many of the amino acids in the motif were highly conserved (Fig. 7, Supplementary Fig. S7).

\section{Discussion}

The sponge gourd is an important vegetable and medicinal plant in tropical and subtropical regions. Plant height is one of the most important traits in Cucurbitaceae breeding. Dwarfism can save labor in management and harvesting, improve lodging resistance and increase the harvest index (Peng et al. 1999). To our knowledge, no prior research about dwarfism in the sponge gourd has been conducted. In this study, we first identified a GAs biosynthetic-deficient dwarf mutant WJ209 in which the cell size and internode numbers decreased (Fig. 1). A genetic analysis revealed that the phenotype is controlled by a single recessive gene. We quickly located and cloned the target gene Lacdl using BSA-Seq and found that the gene is essential for bioactive gibberellin biosynthesis. In combination with RNA-Seq, we found that many genes, including the response to plant hormones, cellular process, cell wall, membrane and response to 


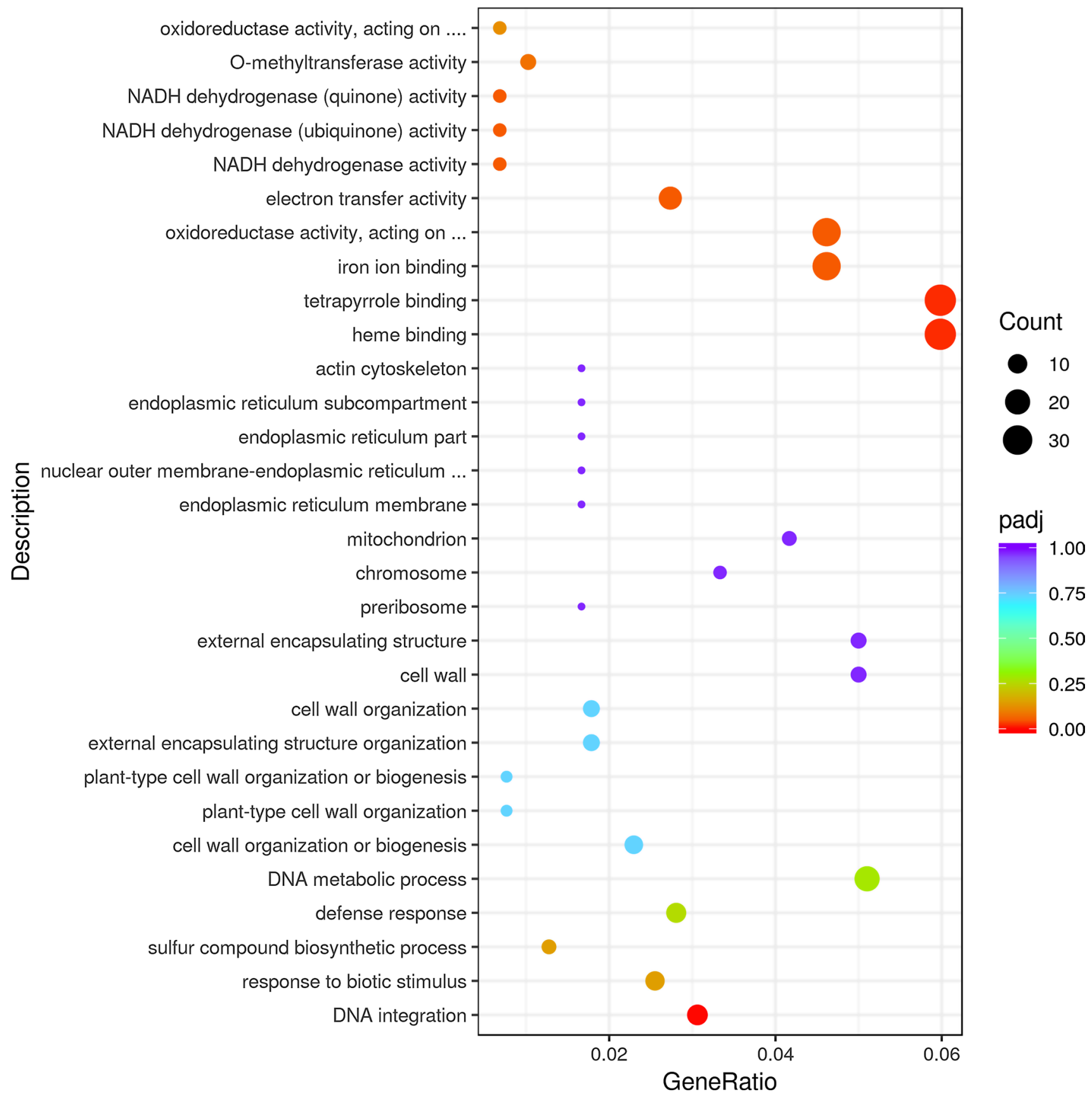

Fig. 5 GO terms of the DEGs in WJ209 compared to WT

stress, were significantly altered in the dwarf mutant WJ209. This study could aid in the use of molecular marker-assisted breeding in dwarf sponge gourd.

There are various reasons that a plant might exhibit a dwarf phenotype, but GAs are one of the most important (Sasaki et al. 2002). Studies have shown that GA3ox catalyzes $\mathrm{GA}_{9}$ and $\mathrm{GA}_{20}$ without biological activity toward bioactive $\mathrm{GA}_{1}$ and $\mathrm{GA}_{4}$ (Hedden and Proebsting 1999). The bioactive synthesis of GAs is blocked in the GA3ox mutant, which affects the elongation of plant cells and causes plant dwarfing (Ágnes et al. 2008; Chen et al. 2014; Mitchum et al. 2006). In this study, the level of $\mathrm{GA}_{1}, \mathrm{GA}_{3}$ and $\mathrm{GA}_{4}$ decreased significantly compared with that in WT (Fig. 2c). This showed that WJ209 is a GAs biosynthetic-deficient mutant. A combination of DNA and RNA sequencing showed that the large fragment insertion of Lacd1 (LacGA3oxl) in WJ209 prevented it from correctly encoding the amino acid, resulting in the loss of the function of GA3 oxidase and reduced contents of bioactive 
Fig. 6 Analysis of the expression of GA biosynthetic and signaling pathways (a) and genes regulated by GAs

(b). The numbers above the column are $\log 2$ [Foldchange (WJ209/WT)]. The asterisks indicate significant differences (Student's $t$ test): *padj $<0.05$,

$* *$ padj $<0.01$
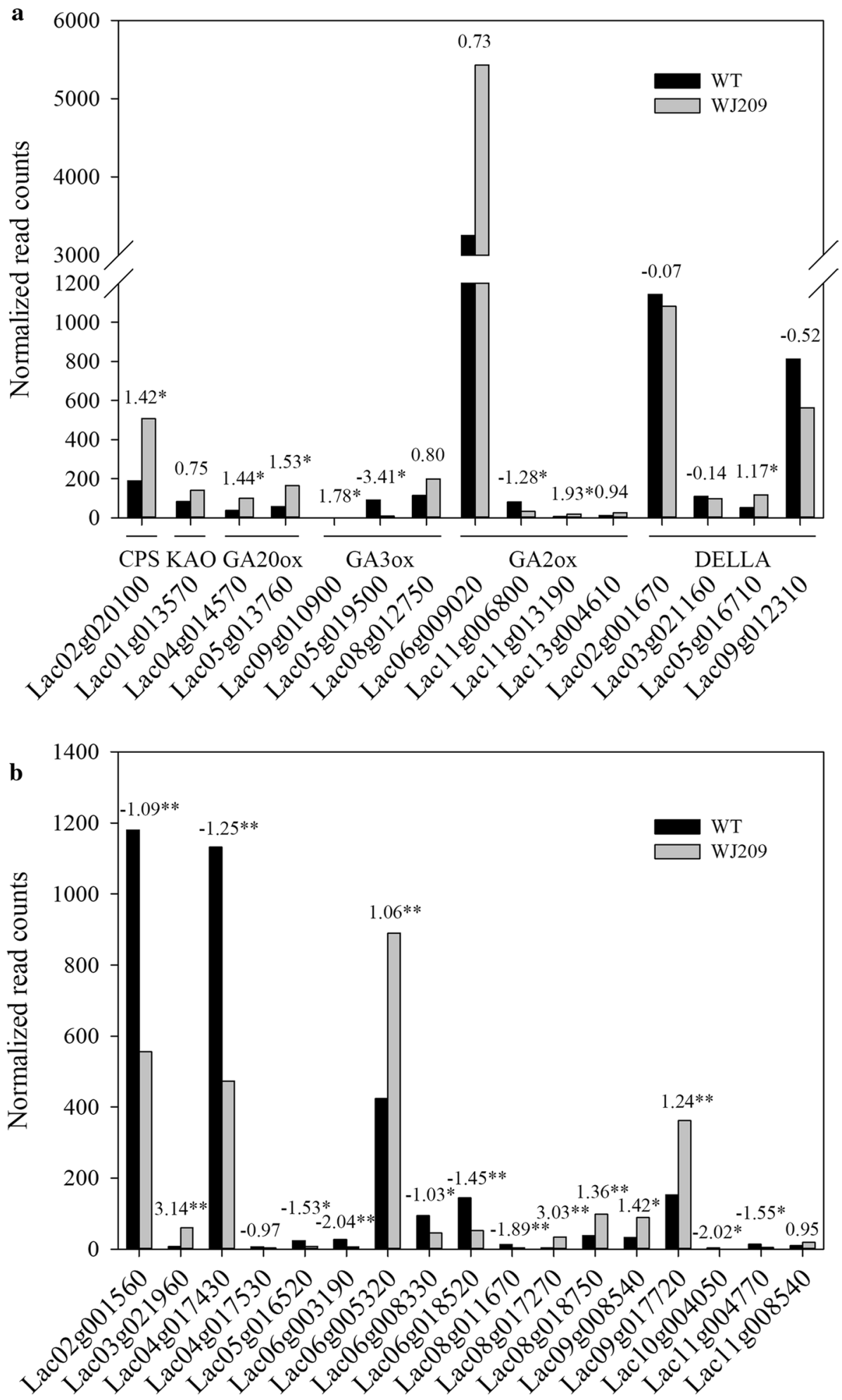

GAs, which is responsible for the dwarfism phenotype in sponge gourd line WJ209.

It is a complex process to synthesize bioactive gibberellin (Claeys et al. 2014; Hedden and Proebsting 1999). In this study, the expression of CPS, KO, GA20oxs and another GA3ox homolog increased in WJ209 (Fig. 6), and the levels of $\mathrm{GA}_{9}$ and $\mathrm{GA}_{20}$ increased, while the bioactive $\mathrm{GA}_{1}, \mathrm{GA}_{3}$ and $\mathrm{GA}_{4}$ decreased (Fig. 2c). The same phenomenon was observed in previous work (Regnault et al. 2014; Shao et al. 2020; Wei et al. 2019), thus suggesting that there may be feedback regulation in GA biosynthesis. It is essential for plants to be able to precisely regulate their content of GAs 


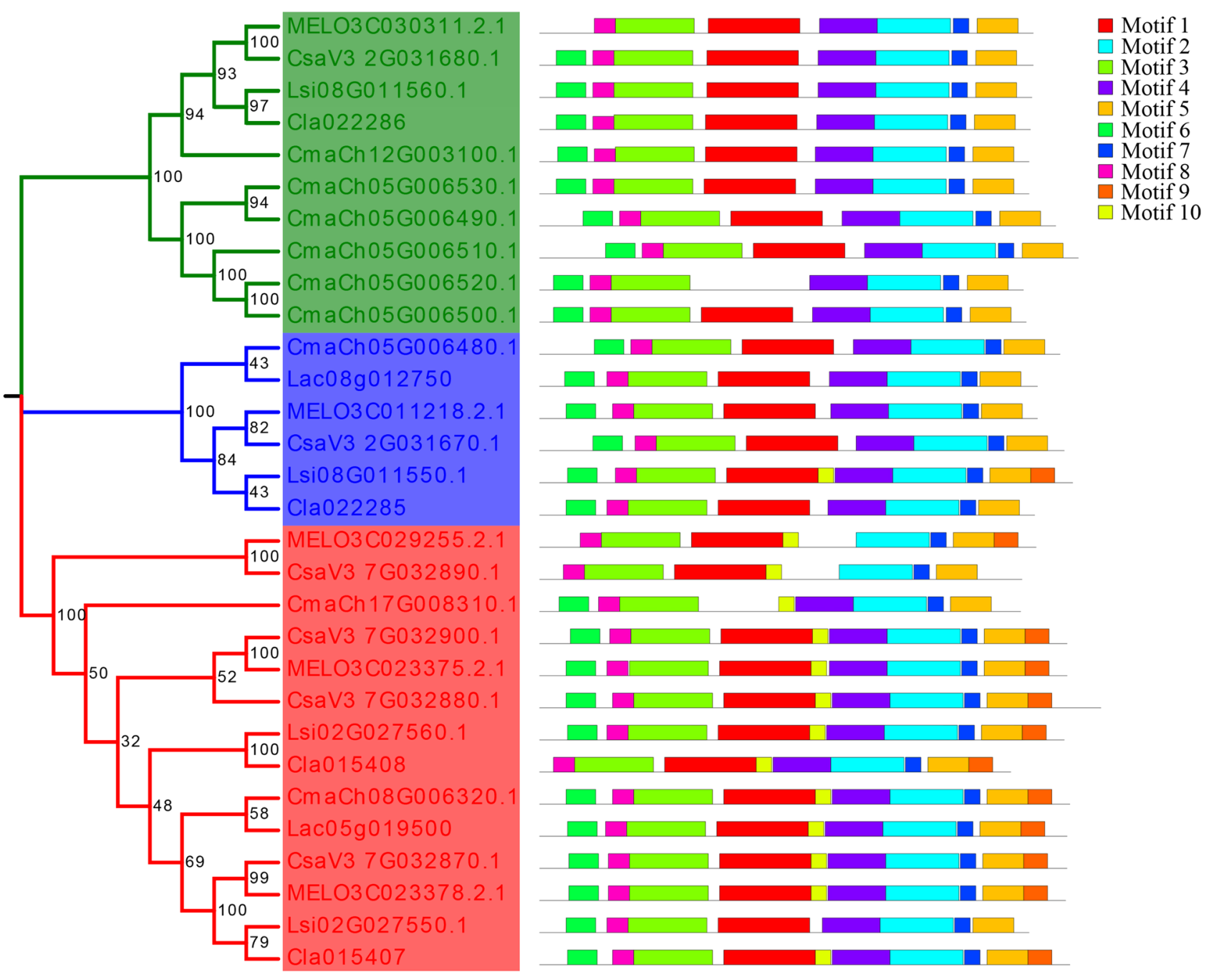

Fig. 7 Phylogenetic and motif analyses of the GA3ox gene family in the sponge gourd and other species of Cucurbitaceae

and possess the ability to rapidly change this parameter in response to changes in their environment (Hedden and Thomas 2012). GA2oxs transforms bioactive gibberellin into inactive gibberellin and convert $\mathrm{GA}_{9}$ and $\mathrm{GA}_{20}$, which are substrates of GA3oxs, to $\mathrm{GA}_{29}$ and $\mathrm{GA}_{51}$ to regulate homoeostasis and allow a rapid reduction of the concentration of bioactive GAs when required (Aragão et al. 2017). In this study, the expression of three GA2oxs was up-regulated in WJ209 (Fig. 6). However, one GA2ox gene exhibited a distinct pattern of expression (Fig. 6), suggesting that this gene could perform distinct functions. Gibberellins regulate gene expression by promoting the degradation of the transcriptional regulator DELLA proteins (Murase et al. 2008). In our study, the expression of one DELLA gene increased, while the others did not change significantly (Fig. 6). Previous studies have shown that the expression of DELLA increased in GA-deficient mutants (Wei et al. 2019), while some exhibited no changes (Wang et al. 2016; Wei et al. 2019). DELLA played distinct but also overlapping functions in the repression of responses to GAs (Davière and Achard 2013).

A substantial amount of research indicates that plant hormones interact with each other to regulate plant growth and development (Blázquez et al. 2020; Depuydt and Hardtke 2011; Liu et al. 2018; Weiss and Ori 2007). Auxin promotes cell elongation partly by promoting GA3oxs and GA20oxs, inhibiting GA2oxs to increase the synthesis of GAs, and promoting the degradation of DELLAs which serve as negative regulators of the GAs signaling pathway, and then enhances GAs signaling pathway(Fu and Harberd 2003; Weiss and Ori 2007). Brassinosteroids (BRs) and GAs promote many similar developmental responses in plants, and BRs and GAs crosstalk through a direct interaction between GAinactivated DELLA and BR-activated BZR1 (Bai et al. 2012; Nolan et al. 2020). Abscisic acid (ABA) and GAs control 
seed germination and the establishment of photoautotrophy by their antagonistic activity (Chen et al. 2020; Liu et al. 2019; Miao et al. 2019). In this study, a number of genes related to the hormone signaling pathway were significantly changed in WJ209 (Supplementary Fig. S6). For example, genes involved in the auxin and ABA signaling pathway were up-regulated, while those in the BR signaling pathway were down-regulated. These results showed that the hormones interacted and then regulated the expression of genes related to the cell wall, membrane and cellular process.

In recent years, an increasing amount of evidence shows that gibberellins are involved in the plant response to abiotic stress, including cold, salt and osmotic stress (Achard et al. 2006; Colebrook et al. 2014; Wang et al. 2020). Reducing the level of bioactive GAs in a GA-deficient biosynthetic mutant and blocking GAs signal transduction in a quadrupledella mutant enhanced the survival rate when Arabidopsis thaliana was subjected to salt and cold stress (Achard et al. 2006; Achard et al. 2008). In this study, many of the genes enriched in GO terms, including the responses to stress, stimuli and defense, were significantly altered in the dwarf mutant WJ209 (Fig. 5, Supplementary Tables S4 and S5). This finding improves our understanding of the potential mechanisms by which GAs modulate stress tolerance.

ATP-dependent caseinolytic proteases (Clp) in higher plants are important for chloroplast function and plant development (Mamaeva et al. 2020; Nishimura et al. 2015). Knockdown or mutant $c l p$ can affect the synthesis of chloroplast and eventually lead to yellow leaf in Arabidopsis (Clarke et al. 2005; Nishimura et al. 2015) and tobacco (Moreno et al. 2017). The growth of GA-deficient mutants of Arabidopsis (Dayan et al. 2010), rice (Sakamoto et al. 2004) and maize (Chen et al. 2014) resulted in production of dark-green leaves. We also found that the leaves of WJ209 turned dark-green (Supplementary Fig. S1). GO terms analyses showed that many of the up-regulated genes were enriched in the chloroplastic endopeptidase Clp complex (GO:0009840) and chloroplast (GO:0009507) (Supplementary Table S5). These probably increase the the content of chloroplast in WJ209, then increased chlorophyll content. This finding suggests that GA may affect chloroplast formation by regulating these genes.

\section{Conclusions}

Using a BSA-Seq strategy, we identified a dwarf mutant gene, designated Lacdl, from a sponge gourd dwarf mutant (WJ209). Our results show that Lacdl encodes a GA3ox, which is one of the key enzymes in the GAs biosynthetic pathway. Sequencing analysis showed that there was an approximately $4 \mathrm{~kb}$ insertion in the first intron of the Lacdl gene in WJ209. This insertion caused incorrect transcription of the Lacdl gene, resulting in the reduced amount of bioactive GAs in WJ209, which is responsible for the dwarfism phenotype in sponge gourd.

Supplementary Information The online version contains supplementary material available at (https://doi.org/10.1007/s00122-021-03938-4).

Author Contribution statement H.W. and G.Z. designed the study and wrote the manuscript. G.Z. and C.L. performed most of the experiments and analyzed the data. G.Z., J.L. and H.G. performed genetic analysis. J.L. and X.Z. helped with the data analysis. X.L. and J.G. prepared and handled samples. G.Z., H.W. and L.Z. revised the manuscript. All authors have read and approved the final paper.

Funding This work was funded by the National Natural Science Foundation of China (31872093, 31902011), the Science and Technology Program of Guangdong Province (2021A1515012500, 2019 A1515010723, 2019A050520002, 2018B020202007, 201904020012, 2019KJ110, 2019A050507003, 2017B030314111), the Science and Technology Program of Guangzhou of China (201807010033), the National Modern Agricultural Technology System Construction Project (CARS-25-G-36), the Project of Research and Application of Commercial Breeding Techniques of Characteristic Cucurbit in South China, the Special fund for scientific innovation strategy-construction of high level Academy of Agriculture Science, Discipline team construction projects of the 14th Five-year Plan (202103TD, 202114TD), and the Project of President Funding of Guangdong Academy of Agricultural Sciences (202005).

Data availability The raw resequencing and transcriptome sequencing data are available from the NCBI under the project ID PRJNA606857.

\section{Declarations}

Conflict of interests The authors declare that they have no conflict of interest.

Ethical approval Not applicable.

Open Access This article is licensed under a Creative Commons Attribution 4.0 International License, which permits use, sharing, adaptation, distribution and reproduction in any medium or format, as long as you give appropriate credit to the original author(s) and the source, provide a link to the Creative Commons licence, and indicate if changes were made. The images or other third party material in this article are included in the article's Creative Commons licence, unless indicated otherwise in a credit line to the material. If material is not included in the article's Creative Commons licence and your intended use is not permitted by statutory regulation or exceeds the permitted use, you will need to obtain permission directly from the copyright holder. To view a copy of this licence, visit http://creativecommons.org/licenses/by/4.0/.

\section{References}

Achard P, Cheng H, De Grauwe L, Decat J, Schoutteten H, Moritz T, Van Der Straeten D, Peng J, Harberd NP (2006) Integration of plant responses to environmentally activated phytohormonal signals. Science 311:91-94

Achard P, Gong F, Cheminant S, Alioua M, Hedden P, Genschik P (2008) The cold-inducible CBF1 factor-dependent signaling 
pathway modulates the accumulation of the growth-repressing DELLA proteins via its effect on gibberellin metabolism. Plant Cell 20:2117-2129

Ágnes Dalmadi, Péter Kaló, Júlia Jakab, Anikó Saskői, Tünde Petrovics (2008) Dwarf plants of diploid Medicago sativa carry a mutation in the gibberellin 3- $\beta$-hydroxylase gene. Plant Cell Rep 27:1271-1279

Andrews S (2010) FastQC: a quality control tool for high throughput sequence data. http://www.bioinformatics.babraham.ac.uk/proje cts/fastqc/

Aragão VPM, Reis RS, Silveira V, Santa-Catarina C (2017) Putrescine promotes changes in the endogenous polyamine levels and proteomic profiles to regulate organogenesis in Cedrela fissilis Vellozo (Meliaceae). Plant Cell Tiss Org 130:495-505

Bai MY, Shang JX, Oh E, Fan M, Bai Y, Zentella R, Sun TP, Wang ZY (2012) Brassinosteroid, gibberellin and phytochrome impinge on a common transcription module in Arabidopsis. Nat Cell Biol 14:810-817

Bentley DR (2006) Whole-genome re-sequencing. Curr Opin Gene Dev 16:545-552

Blázquez MA, Nelson DC, Weijers D (2020) Evolution of plant hormone response pathways. Annu Rev Plant Bio 71(1):327-353

Chen Y, Hou M, Liu L, Wu S, Shen Y, Ishiyama K, Kobayashi M, McCarty DR, Tan BC (2014) The maize DWARF1 encodes a gibberellin 3-oxidase and is dual localized to the nucleus and cytosol. Plant Physiol 166:2028-2039

Chen H, Ruan J, Chu P, Fu W, Liang Z, Li Y, Tong J, Xiao L, Liu J, Li C, Huang S (2020) AtPER1 enhances primary seed dormancy and reduces seed germination by suppressing the ABA catabolism and GA biosynthesis in Arabidopsis seeds. Plant J 101:310-323

Chory J, Nagpal P, Peto CA (1991) Phenotypic and genetic analysis of $\operatorname{det} 2$, a new mutant that affects light-regulated seedling development in Arabidopsis. Plant Cell 3:445-459

Claeys H, De Bodt S, Inze D (2014) Gibberellins and DELLAs: central nodes in growth regulatory networks. Trends Plant Sci 19:231-239

Clarke AK, MacDonald TM, Sjögren LLE (2005) The ATP-dependent Clp protease in chloroplasts of higher plants. Physiol Plantarum 123:406-412

Colebrook EH, Thomas SG, Phillips AL, Hedden P (2014) The role of gibberellin signalling in plant responses to abiotic stress. J Exp Biol 217:67-75

Davière J-M, Achard P (2013) Gibberellin signaling in plants. Development 140:1147-1151

Dayan J, Schwarzkopf M, Avni A, Aloni R (2010) Enhancing plant growth and fiber production by silencing GA 2-oxidase. Plant Biotechnol J 8:425-435

Depuydt S, Hardtke CS (2011) Hormone signalling crosstalk in plant growth regulation. Curr Biol 21:R365-R374

Dong W, Wu D, Li G, Wu D, Wang Z (2018) Next-generation sequencing from bulked segregant analysis identifies a dwarfism gene in watermelon. Sci Rep-UK 8:2908

Dubey S, Saha S, Kaithwas G, Saraf SA (2015) Effect of standardized fruit extract of Luffa cylindrica on oxidative stress markers in hydrogen peroxide induced cataract. Indian J Pharmacol 47:644-648

Fambrini M, Mariotti L, Parlanti S, Picciarelli P, Salvini M, Ceccarelli N, Pugliesi C (2011) The extreme dwarf phenotype of the GAsensitive mutant of sunflower, $d w a r f 2$, is generated by a deletion in theent-kaurenoic acid oxidase1 (HaKAOl) gene sequence. Plant Mol Biol 75:431-450

Fu X, Harberd NP (2003) Auxin promotes Arabidopsis root growth by modulating gibberellin response. Nature 421:740-743
Gautam A et al (2017) Genetic divergence and character association studies in indegenous ridge gourd (Luffa Acutangula (L.) Roxb) Genotypes. J Pharm Phytochem 6:1769-1774

Hedden P, Proebsting W (1999) Genetic analysis of gibberellin biosynthesis. Plant Physiol 119:365-370

Hedden P, Thomas SG (2012) Gibberellin biosynthesis and its regulation. Biochem J 444:11-25

Hexun H, Xiaoqi Z, Zhencheng W, Qinghuai L, Xi L (1998) Inheritance of male-sterility and dwarfism in watermelon [Citrullus lanatus (Thunb.) Matsum. and Nakai]. Sci Hortic-Amst 74:175-181

Hou S, Niu H, Tao Q, Wang S, Gong Z, Li S, Weng Y, Li Z (2017) A mutant in the CsDET2 gene leads to a systemic brassinosteriod deficiency and super compact phenotype in cucumber (Cucumis sativus L.). Theor Appl Genet 130:1693-1703

Hwang J, Oh J, Kim Z, Staub JE, Chung S-M, Park Y (2014) Fine genetic mapping of a locus controlling short internode length in melon (Cucumismelo L.). Mol Breed 34:949-961

Kalloo G (1993) Loofah: Luffa spp. genetic improvement of vegetable crops. Pergamon Press, Oxford, pp 265-266

Khush GS (2001) Green revolution: the way forward. Nat Rev Genet 2:815-822

Kim D, Langmead B, Salzberg SL (2015) HISAT: a fast spliced aligner with low memory requirements. Nat Methods 12:357-360

Kohlen W, Charnikhova T, Lammers M, Pollina T, Tóth P, Haider I, Pozo MJ, de Maagd RA, RuyterSpira C, Bouwmeester HJ, LópezRáez JA (2012) The tomato CAROTENOID CLEAVAGE DIOXYGENASE8 (SICCD8) regulates rhizosphere signaling, plant architecture and affects reproductive development through strigolactone biosynthesis. New Phytol 196:535-547

Kumar S, Stecher G, Tamura K (2016) MEGA7: Molecular evolutionary genetics analysis version 7.0 for bigger datasets. Mol Biol Evol 33:1870-1874

Kuppast IJ, Mankani KL (2012) A review on Luffa acutangula. Nat Prod Ind J 8:198-193

Larkin MA, Blackshields G, Brown NP, Chenna R, McGettigan PA, McWilliam H, Valentin F, Wallace IM, Wilm A, Lopez R, Thompson JD, Gibson TJ, Higgins DG (2007) Clustal W and clustal X version 2.0. Bioinformatics 23:2947-2948

Li A, Yang W, Li S, Liu D, Guo X, Sun J, Zhang A (2013) Molecular characterization of three GIBBERELLIN-INSENSITIVE $D W A R F 1$ homologous genes in hexaploid wheat. J Plant Physiol 170:432-443

Li H, Durbin R (2009) Fast and accurate short read alignment with burrows-WHEELER transform. Bioinformatics 25:1754-1760

Li H, Handsaker B, Wysoker A, Fennell T, Ruan J, Homer N, Marth G, Abecasis G, Durbin R, Genome Project Data Processing S (2009) The sequence alignment/map format and SAMtools. Bioinformatics 25(2078):2079

Li Y, Yang L, Pathak M, Li D, He X, Weng Y (2011) Fine genetic mapping of $c p$ : a recessive gene for compact (dwarf) plant architecture in cucumber, Cucumis sativus L. Theor Appl Genet 123:973

Li Y, Xu A, Dong W, Li Z, Li G (2016) Genetic analysis of a dwarf vine and small fruit watermelon mutant. Horiz Plant J 2:224-228

Li Z, Zhang X, Zhao Y, Li Y, Zhang G, Peng Z, Zhang J (2018) Enhancing auxin accumulation in maize root tips improves root growth and dwarfs plant height. Plant Biotechnol J 16:86-99

Liao Y, Smyth GK, Shi W (2014) featureCounts: an efficient general purpose program for assigning sequence reads to genomic features. Bioinformatics 30:923-930

Liu L, Wang Z, Liu J, Liu F, Zhai R, Zhu C, Wang H, Ma F, Xu L (2018) Histological, hormonal and transcriptomic reveal the changes upon gibberellin-induced parthenocarpy in pear fruit. Hortic Res 5:1-13

Liu H, Guo S, Lu M, Zhang Y, Li J, Wang W, Wang P, Zhang J, Hu Z, Li L, Si L, Zhang J, Qi Q, Jiang X, Botella JR, Wang H, Song 
C-P (2019) Biosynthesis of DHGA12 and its roles in Arabidopsis seedling establishment. Nat Commun 10:1768

Love MI, Huber W, Anders S (2014) Moderated estimation of fold change and dispersion for RNA-seq data with DESeq2. Genome Biol 15:550

Magome H, Yamaguchi S, Hanada A, Kamiya Y, Oda K (2004) Dwarf and delayed-flowering 1, a novel Arabidopsis mutant deficient in gibberellin biosynthesis because of overexpression of a putative AP2 transcription factor. Plant J 37:720-729

Mamaeva A, Taliansky M, Filippova A, Love AJ, Golub N, Fesenko I (2020) The role of chloroplast protein remodeling in stress responses and shaping of the plant peptidome. New Phytol 227(5):1326-1334

McKenna A, Hanna M, Banks E, Sivachenko A, Cibulskis K, Kernytsky A, Garimella K, Altshuler D, Gabriel S, Daly M, DePristo MA (2010) The genome analysis toolkit: a mapreduce framework for analyzing next-generation DNA sequencing data. Genome Res 20:1297-1303

Miao C, Wang Z, Zhang L, Yao J, Hua K, Liu X, Shi H, Zhu J-K (2019) The grain yield modulator miR156 regulates seed dormancy through the gibberellin pathway in rice. Nat Commun 10:1-12

Michelmore RW, Paran I, Kesseli RV (1991) Identification of markers linked to disease-resistance genes by bulked segregant analysis: a rapid method to detect markers in specific genomic regions by using segregating populations. Proc Natl Acad Sci USA 88:9828-9832

Mitchum MG, Yamaguchi S, Hanada A, Kuwahara A, Yoshioka Y, Kato T, Tabata S, Kamiya Y, Sun TP (2006) Distinct and overlapping roles of two gibberellin 3-oxidases in Arabidopsis development. Plant J 45:804-818

Moreno JC, Tiller N, Diez M, Karcher D, Tillich M, Schöttler MA, Bock R (2017) Generation and characterization of a collection of knock-down lines for the chloroplast Clp protease complex in tobacco. J Exp Bot 68:2199-2218

Murase K, Hirano Y, Sun T-p, Hakoshima T (2008) Gibberellininduced DELLA recognition by the gibberellin receptor GID1. Nature 456:459-463

Murray MG, Thompson WF (1980) Rapid isolation of high molecular weight plant DNA. Nucl Acids Res 8:4321-4325

Ng YM, Yang Y, Sze KH, Zhang X, Zheng YT, Shaw PC (2011) Structural characterization and anti-HIV-1 activities of arginine/ glutamate-rich polypeptide Luffin P1 from the seeds of sponge gourd (Luffa cylindrica). J Struct Biol 174:164-172

Nishimura K, Apitz J, Friso G, Kim J, Ponnala L, Grimm B, van Wijk KJ (2015) Discovery of a unique Clp Component, ClpF, in chloroplasts: a proposed binary $\mathrm{ClpF}-\mathrm{ClpS} 1$ adaptor complex functions in substrate recognition and delivery. Plant Cell 27:2677-2691

Nolan TM, Vukašinović N, Liu D, Russinova E, Yin Y (2020) Brassinosteroids: multidimensional regulators of plant growth, development, and stress responses. Plant Cell 32:295-318

Peng J, Richards DE, Hartley NM, Murphy GP, Devos KM, Flintham JE, Beales J, Fish LJ, Worland AJ, Pelica F, Sudhakar D, Christou P, Snape JW, Gale MD, Harberd NP (1999) 'Green revolution' genes encode mutant gibberellin response modulators. Nature 400:256-261

Plackett ARG, Powers SJ, Fernandez-Garcia N, Urbanova T, Takebayashi Y, Seo M, Jikumaru Y, Benlloch R, Nilsson O, RuizRivero O, Phillips AL, Wilson ZA, Thomas SG, Hedden P (2012) Analysis of the developmental roles of the Arabidopsis gibberellin 20-Oxidases demonstrates that GA20ox1, -2, and -3 are the dominant paralogs. Plant Cell 24:941-960

Regnault T, Daviere JM, Heintz D, Lange T, Achard P (2014) The gibberellin biosynthetic genes AtKAO1 and AtKAO2 have overlapping roles throughout Arabidopsis development. Plant J 80:462-474
Robinson JT, Thorvaldsdóttir H, Winckler W, Guttman M, Lander ES, Getz G, Mesirov JP (2011) Integrative genomics viewer. Nat Biotechnol 29:24-26

Sakamoto T, Miura K, Itoh H, Tatsumi T, Ueguchi-Tanaka M, Ishiyama K, Kobayashi M, Agrawal GK, Takeda S, Abe K, Miyao A, Hirochika H, Kitano H, Ashikari M, Matsuoka M (2004) An overview of gibberellin metabolism enzyme genes and their related mutants in rice. Plant Physiol 134:1642-1653

Sasaki A, Ashikari M, Ueguchi-Tanaka M, Itoh H, Nishimura A, Swapan D, Ishiyama K, Saito T, Kobayashi M, Khush GS (2002) Green revolution: a mutant gibberellin-synthesis gene in rice. Nature 416:701-702

Schwessinger B, Roux M, Kadota Y, Ntoukakis V, Sklenar J, Jones A, Zipfel C (2011) Phosphorylation-dependent differential regulation of plant growth, cell death, and innate immunity by the regulatory receptor-like kinase BAK1. Plos Genet 7:e1002046

Shao X, Wu S, Dou T, Zhu H, Hu C, Huo H, He W, Deng G, Sheng O, Bi F, Gao H, Dong T, Li C, Yang Q, Yi G (2020) Using CRISPR/ Cas9 genome editing system to create MaGA20ox2 gene-modified semi-dwarf banana. Plant Biotechnol J 18:17-19

Shendge PN, Belemkar S (2018) Therapeutic potential of Luffa acutangula: A review onits traditional uses, phytochemistry, pharmacology and toxicological aspects. Front Pharmacol 9:1177

Shimada A, Ueguchi-Tanaka M, Nakatsu T, Nakajima M, Naoe Y, Ohmiya H, Kato H, Matsuoka M (2008) Structural basis for gibberellin recognition by its receptor GID1. Nature 456:520-523

Silverstone AL, Sun T (2000) Gibberellins and the green revolution. Trends Plant Sci 5:1-2

Song M, Zhang M, Cheng F, Wei Q, Wang J, Davoudi M, Chen J, Lou Q (2020) An irregularly striped rind mutant reveals new insight into the function of PG1 $\beta$ in cucumber (Cucumis sativus L.). Theor Appl Genet 133:371-382

Suh HS (1978) The segregation mode of plant height in the cross of rice varieties. II. Linkage analysis of the semi-dwarfness of rice variety "Tongil." Korean J Breed 10:1-6

Sun J, Wang H, Ren L, Chen S, Chen F, Jiang J (2017) CmFTL2 is involved in the photoperiod- and sucrose-mediated control of flowering time in chrysanthemum. Hortic Res 4:17001

Takagi H, Abe A, Yoshida K, Kosugi S, Natsume S, Mitsuoka C, Uemura A, Utsushi H, Tamiru M, Takuno S, Innan H, Cano LM, Kamoun S, Terauchi R (2013) QTL-seq: rapid mapping of quantitative trait loci in rice by whole genome resequencing of DNA from two bulked populations. Plant J 74:174-183

Ueguchi-Tanaka M, Ashikari M, Nakajima M, Itoh H, Katoh E, Kobayashi M, Chow TY, Hsing YI, Kitano H, Yamaguchi I, Matsuoka M (2005) GIBBERELLIN INSENSITIVE DWARF1 encodes a soluble receptor for gibberellin. Nature 437:693-698

Wang G-L, Xiong F, Que F, Xu Z-S, Wang F, Xiong A-S (2015) Morphological characteristics, anatomical structure, and gene expression: novel insights into gibberellin biosynthesis and perception during carrot growth and development. Hortic Res 2:15028

Wang Y, Lu W, Chen Y, Deng D, Ding H, Bian Y, Yin Z, Zhu Y, Zhao J (2016) Revealing physiological and genetic properties of a dominant maize dwarf Dwarf11 (D11) by integrative analysis. Mol Breed 36:31

Wang J, Qin H, Zhou S, Wei P, Zhang H, Zhou Y, Miao Y, Huang R (2020) The ubiquitin-binding protein OsDSK2a mediates seedling growth and salt responses by regulating gibberellin metabolism in rice. Plant Cell 32:414-428

Wei C, Zhu C, Yang L, Zhao W, Ma R, Li H, Zhang Y, Ma J, Yang J, Zhang X (2019) A point mutation resulting in a 13 bp deletion in the coding sequence of $C l d f$ leads to a GA-deficient dwarf phenotype in watermelon. Hortic Res 6:1-12

Weiss D, Ori N (2007) Mechanisms of cross talk between gibberellin and other hormones. Plant Physiol 144:1240-1246 
Wu HB, Gong H, Liu P, He XL, Luo SB, Zheng XM, Zhang CY, He XM, Luo JN (2014) Large-scale development of EST-SSR markers in sponge gourd via transcriptome sequencing. Mol Breed 34:1903-1915

Wu HB, He XL, Gong H, Luo SB, Li MZ, Chen JQ, hang CY, Yu T, Huang WP, Luo JN (2016) Genetic linkage map construction and QTL analysis of two interspecific reproductive isolation traits in sponge gourd. Front Plant Sci 7:980

Xu S, Hu J, Tan H, Zhang S (2008) Effects of genotype and environment on vitamin $\mathrm{C}$ content and its heterosis in towel gourd fruits. J Sci Food Agr 88:290-293

Zhai R, Wang Z, Yang C, Lin-Wang K, Espley R, Liu J, Li X, Wu Z, Li P, Guan Q, Ma F, Xu L (2019) PbGA2ox8 induces vascularrelated anthocyanin accumulation and contributes to red stripe formation on pear fruit. Hortic Res 6:137

Zhang G, Ren Y, Sun H, Guo S, Zhang F, Zhang J, Zhang H, Jia Z, Fei $\mathrm{Z}, \mathrm{Xu} \mathrm{Y,} \mathrm{Li} \mathrm{H} \mathrm{(2015)} \mathrm{A} \mathrm{high-density} \mathrm{genetic} \mathrm{map} \mathrm{for} \mathrm{anchoring}$ genome sequences and identifying QTLs associated with dwarf vine in pumpkin (Cucurbita maxima Duch). BMC Genom. https:// doi.org/10.1186/s12864-015-2312-8

Zhang T, Liu J, Liu S, Ding Z, Luan F, Gao P (2019) Bulked-segregant analysis identified a putative region related to short internode length in melon. Hort Sci 54:1293

Zou C, Wang P, Xu Y (2016) Bulked sample analysis in genetics, genomics and crop improvement. Plant Biotechnol J 14:1941-1955

Publisher's Note Springer Nature remains neutral with regard to jurisdictional claims in published maps and institutional affiliations. 